\title{
The Student-Centered STEM Learning Model Based on Artificial Intelligence Project: A Case Study on Intelligent Car
}

\author{
https://doi.org/10.3991/ijet.v16i21.25105 \\ Jianxin Liao, Jingmin Yang( $\left.{ }^{(}\right)$, Wenjie Zhang \\ Minnan Normal University, Zhangzhou, P.R.China \\ Fujian Province University, Fuzhou, P.R.China \\ yjm1758@mnnu.edu.cn
}

\begin{abstract}
Artificial intelligence has become a crucial technology for the development of the times. In the practice of emerging engineering education about artificial intelligence, how to enhance students' understanding of artificial intelligence technology, strengthen students' enthusiasm for learning, and improve their innovation ability is a key issue. This research constructs a novel Student-Centered STEM Learning Model (SC-STEM-LM), compensating for engineering students' lack of innovative practice in high education. First, students use real projects as the background to find technical literature and make learning plans. Then, they carry out four STEM learning activities at the same time in cooperation. Finally, the students cultivate their innovation ability by improving the performance of the project. Furthermore, taking the intelligent car target tracking system as an example, we voluntarily recruit ten students with similar abilities from the school of computer science and randomly divide them into two groups (experimental group and control group) to verify the learning effect. In addition, to objectively evaluate the actual effect of the SCSTEM-LM, we also propose a new weighted multi-evaluation algorithm. The results show that the score of the experimental group is 82.84 , which is 8.86 higher than the control group.
\end{abstract}

Keywords-Artificial Intelligence, Intelligent Car, Multiple Evaluation, Student-Centered STEM Learning Model, STEM Education

\section{$1 \quad$ Introduction}

Artificial intelligence has become a crucial technology leading future development and is rapidly advancing the process of social intelligence [1]. Researchers' interpretation of the Development Plans of the New Generation Artificial Intelligence issued by the Chinese government shows a gap in the development of artificial intelligence in China compared with developed countries [2]. Furthermore, the market has a greater demand for AI talents, and the artificial intelligence education system urgently needs to be improved. Therefore, Educational scholars use artificial intelligence projects to accelerate the reform of learning models, and it is essential to build a new education 
system that includes interactive learning, intelligent learning, and project-based learning [3].

At present, a revolution in the innovation of traditional learning models is also emerging in the education field, namely STEM education. It has profound, essential scientific characteristics and wide application technical characteristics. Students use mathematical knowledge to solve engineering problems and then conduct group discussion activities suitable for cultivating engineering students' research and practical abilities [4]. In addition, artificial intelligence technology has also expanded the scope of influence of STEM. The application of educational robots and intelligent teaching aids has built a brand-new educational ecosystem on campus [5].

For these reasons, how to apply STEM to engineering education is a question worth studying. Many scholars have done a lot of research and achieved remarkable achievements. For example, Stuikys et al. [6] introduced a personalized learning framework in STEM-driven computer courses to help improve engineering education. Tang et al. [7] proposed a STEM interdisciplinary integration model based on artificial intelligence technology in China. However, while changing the learning model, we should pay more attention to students' learning interests and innovation abilities. For example, Papadakis [8] used programming methods to create weather forecast applications for smart mobile devices to help students develop advanced cognitive thinking skills effectively. They combined STEM learning with basic programming concepts and successfully responded to the rapid development of the information society.

Therefore, our research objective is to promote STEM and engineering education integration through a student-centered learning model. In addition, we use artificial intelligence projects as examples, hoping to bring students a sense of experience and harvest [9]. In summary, our research aims to solving engineering students' understanding of complex knowledge, enhancing students' learning enthusiasm, and improving their innovative abilities. Our contributions are mainly in the following bullet points:

1. Put forward a novel Student-Centered STEM Learning Model (SC-STEM-LM) based on artificial intelligence projects, which improves students' problem-solving skills, and innovative abilities.

2. Designed a new weighted multi-evaluation algorithm to measure the learning effects of students in different stages.

The rest of this paper is structured as follows. Section 2 introduces the theoretical framework and research status. Section 3 presents the scope and the learning model's design and provides a new weighted multi-evaluation algorithm. Section 4 designs the project structure and the students' work in detail. Section 5 analyzes and discusses the experimental results. Section 6 is the conclusion, which summarizes the research conclusion and the existing problems of this paper, and puts forward the improvement direction of the further study. 


\section{Literature review}

This section gives a theoretical framework and then analyzes the research status to clarify our research problem and objective.

\subsection{Theoretical framework}

STEM is essentially a multidisciplinary curriculum that integrates science, technology, engineering, and mathematics. It is not a simple superposition of knowledge but an education method that requires a deep integration of interdisciplinary knowledge. To achieve the research objective, the development of the STEM learning model should have the following four characteristics [10]: (1) project-driven as the orientation; (2) interdisciplinary knowledge as the core; (3) frontier science and technology as the support; (4) cooperation Inquiry is a form. For example, Birzina et al. [11] recommend using real cases and projects to increase students' interest in solving problems creatively integrating STEM content. In addition, Almulla [12] thinks There is a significant relationship between project-based learning and collaborative learning, iterative learning, and subject learning. It improves student participation through information sharing and discussion. Based on the above two aspects, we propose a basic theoretical framework, as shown in Fig. 1.

The learning process is roughly divided into four aspects: problem-driven, project design, practical application, and project evaluation. Learners carry out learning activities around specific themes and use various tools and resources to form a learning community. Moreover, our research further promotes the integration of STEM and artificial intelligence education on this basis.

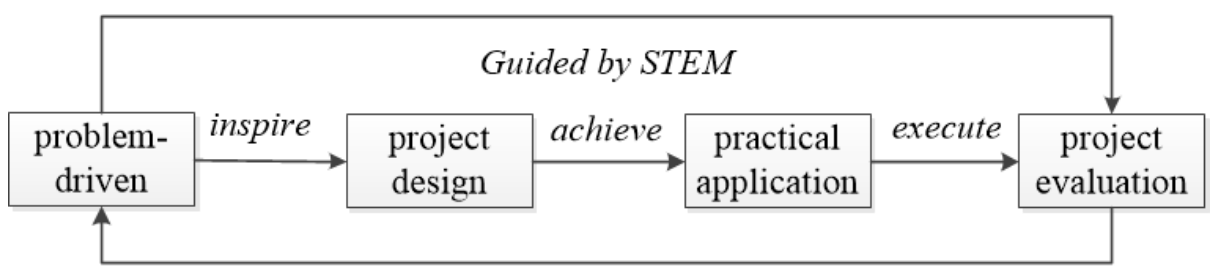

Iterative learning

Fig. 1. The project-based learning model with the STEM theory

\subsection{Research status}

Since the NMC Horizon Report 2017 Higher Education Edition was published, more and more research aims to develop STEM blended learning models. Some experts even pointed out that STEM will become a critical factor in promoting the development of school education [13]. Therefore, we have analyzed the relevant research progress at home and abroad since 2017. 
Most reviews on STEM are positive. However, Yanez et al. [14] believe that North American schools are eager to adopt STEM reforms, obscuring the ecological, moral, and social conditions students face daily. In addition, the main reason for students to complete courses is learning interest, and the government's measures to increase student participation in learning by committing to provide high-quality courses are inefficient [15]. Thus, relevant policies encourage society and schools to innovate STEM learning models [16]. For example, Cheng et al. [17] proposed a STEM learning model based on design thinking to encourage students to cultivate problem-solving abilities in curriculum design.

At the same time, with the widespread application of new forms of educational technology, educational robots can promote a student-centered collaborative environment [18]. The free and pleasant atmosphere it creates encourages STEM education and enhances the learning process. Togou et al. [19] used Fab Labs (Computer Manufacturing Labs) to prove that learners can be more interested in learning and quickly adapt to the new environment. Dasgupta et al. [20] used an Energy3D (Educational Computer-Aided Tool) learning environment to provide formative feedback to help students understand knowledge. To meet the needs of higher education, Jiang et al. [21] have researched stable parallel algorithms for online computer education and designed a STEM robot model to make it easier for students to understand the execution process of computer algorithms. Therefore, the learning environment can affect students' attitudes. Especially the self-efficacy and learning motivation can also affect future career planning [22].

In the background of the new normal of education, researchers designed learning activities with students as the center [23] and combined various emerging technologies such as gamification [24], digital media, and educational robots, which can effectively improve students' interest and performance. However, experienced teachers have negative feelings about using educational robots in formal courses due to uncertainty [25]. It is necessary to strengthen the investment in new education technology, not just theoretical teaching. In addition, there are few studies on learning models at home and abroad to practice innovative ideas in high education. Consequently, future research should explore different learning models [26] to promote STEM and projectbased learning integration.

Inspired by the above research, our research further explored the application model of STEM in engineering education. The problem guiding this research is: enhancing students' understanding of knowledge, strengthening students' learning enthusiasm, and improving their innovative ability.

\section{Design of STEM learning model}

The beginning of this section describes the research scope and sample selection, then introduces the novel learning model proposed in this research, and finally provides a new weighted multi-evaluation algorithm. 


\subsection{Scope}

Because we design the learning model for educational research, not the regular courses set by the college, therefore, under the premise of not affecting the regular teaching plan, we adopt the method of recruiting volunteers. And then, we select ten students with similar abilities from the enrolled students in chronological order and divide them into two groups evenly. The allocation method is systematic random sampling. They are all third-year students from the school of computer science, with similar ages and engineering backgrounds.

The two groups adopt the SC-STEM-LM and traditional learning model, respectively, under the condition of providing the same experimental equipment and completing the necessary project functions. In addition, two instructors participate in the project's evaluation throughout the whole process without interfering with the student's research. Besides, the duration of project learning is six weeks.

\subsection{The student-centered STEM learning model}

The SC-STEM-LM is showed in Fig. 2. The learning model mainly contains seven activities, and the relevant explanations are as follows:

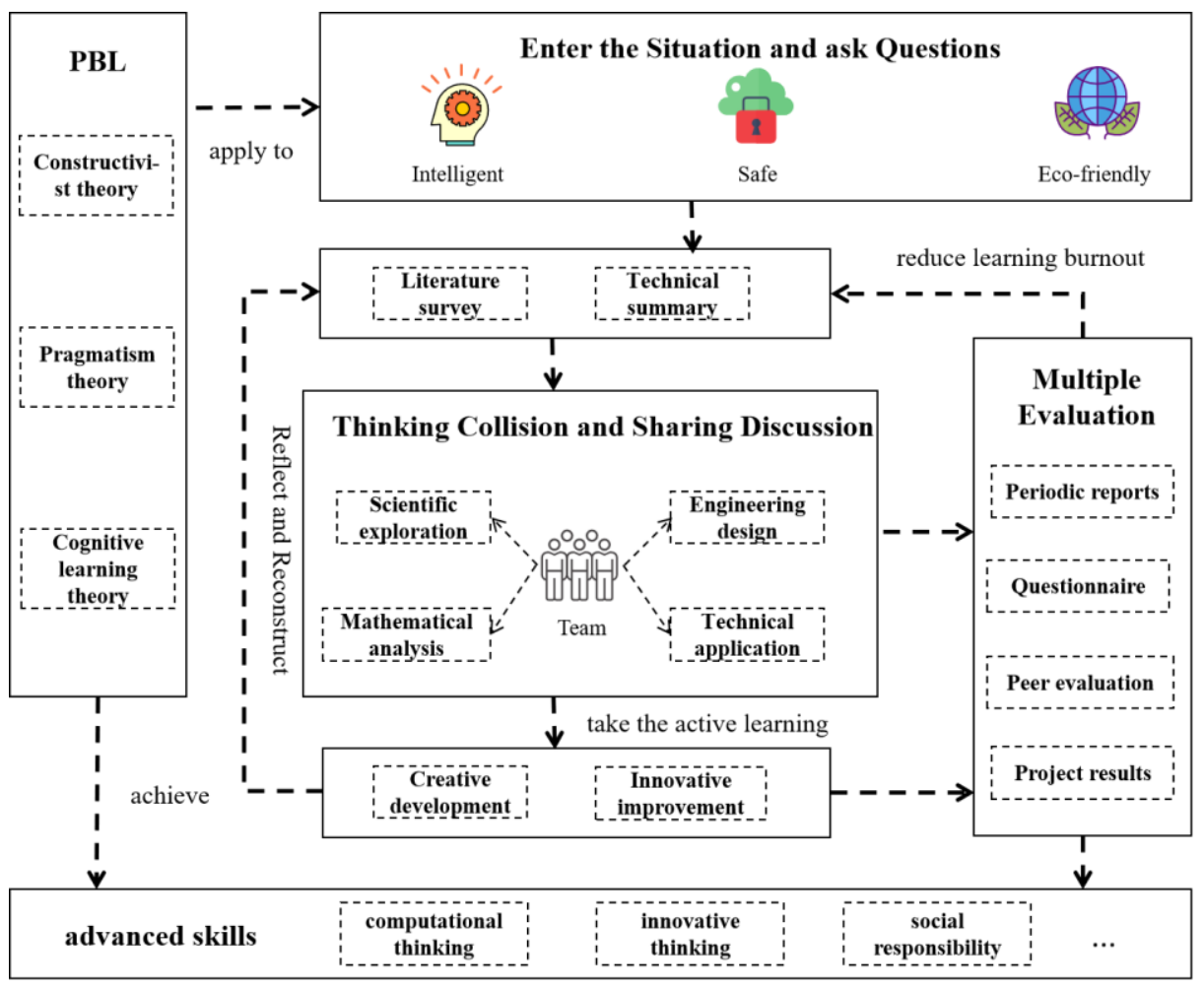

Fig. 2. The student-centered STEM learning model 
1. Enter the situation and ask questions (SQ): Students enter an actual project situation in this activity to get an intelligent, safe, and environmentally friendly project experience. In that case, we hope that students can ask in-depth questions to further their knowledge.

2. Literature survey and technical summary (LS): The learning group needs to search relevant literature according to the needs and functions of the project. Then, each student should understand the cutting-edge technical methods, clarify the current problems, and sort out the technical route. Finally, they need to make a learning plan and strictly implement it.

3. Scientific exploration and mathematical analysis (SM): Students should conduct scientific investigations around specific project functions and use mathematical methods to find answers in this learning activity. The purpose of this is to make students understand knowledge and learn to use mathematical language to describe the essential characteristics of the project.

4. Engineering design and technology application (ET): This learning activity is conducted simultaneously with SM. Unlike SM, ET activities pay more attention to students' practical operations. We require students to study in practice, verify the feasibility of theoretical reasoning and obtain the best technical solution.

5. Thinking Collision and sharing discussion (TS): The design of this activity is a bridge between theory and practice. Because both scientific approach and engineering experience should be valued, in that case, students can conduct intense discussions in mutual evaluation to collide with sparks of thinking.

6. Creative development and innovative improvement (CI): This activity is to help students get out of their comfort zone and break through the bottleneck of technology. We try to continuously guide students to get in touch with knowledge in other fields to cultivate innovative and critical thinking. Therefore, students should learn to discover problems, reflect on the results of experiments, and reconstruct their knowledge system.

7. Multiple evaluations and empirical analysis (EA): This activity is to verify the effectiveness of the learning model. Eventually, we hope to achieve the development of students' advanced skills.

\subsection{Multiple evaluation}

In higher education, the complexity of the learning process brings considerable challenges to the evaluation system. Because traditional evaluation methods are too simplistic, it ignores the cultivation of core literacy in the learning process [27]. For this reason, we incorporate a weighted multi-evaluation algorithm into the STEM learning model, including four aspects: periodic report, questionnaire, peer evaluation, and project results. Similarly, this also applies to traditional project-based learning.

The weighted multi-evaluation algorithm takes students as the main body and examines the learning process with multiple factors, as shown in Table 1. . We can measure learning effects and solve our research problems by evaluating and analyzing instructors, peers, individuals, and project results. To show the final total achieve- 
ment, we use a weighted sum algorithm. The proportion of each item is $30 \%, 20 \%$, $20 \%$, and $30 \%$.

Periodic Reports. There are three rounds of periodic meeting reports from the perspective of instructors. Each group of students reports on the project learning situation separately, which mainly examines the students' understanding of the project knowledge. Then, the instructors evaluate based on the content of the submitted materials and the students' ability to express and summarize and score in five grades from A to E. After three rounds of evaluation, we count the total score of the two learning groups, take the average of the scores of the two instructors and convert them into a hundred-point system to get the periodic reports results.

Table 1. Multi-evaluation of project-based learning

\begin{tabular}{|c|c|c|}
\hline Evaluation Method & Contents & Weights \\
\hline \multirow[t]{2}{*}{ E1: Periodic Reports } & $\begin{array}{l}\text { Check the completeness of the document and the content of the } \\
\text { writing }\end{array}$ & \multirow[t]{2}{*}{$30 \%$} \\
\hline & Investigate students' ability to express and summarize & \\
\hline \multirow{3}{*}{ E2: Questionnaire } & Learning interest in the project & \multirow{3}{*}{$20 \%$} \\
\hline & Understanding of subject knowledge & \\
\hline & Engineering project competencies & \\
\hline \multirow{2}{*}{ E3: Peer Evaluation } & Emotional type & \multirow{2}{*}{$20 \%$} \\
\hline & Cognitive type & \\
\hline E4: Project Results & The accuracy of the intelligent car to complete the target tracking & $30 \%$ \\
\hline Total Achievement & \multicolumn{2}{|l|}{$\mathrm{E} 1 * 0.3+\mathrm{E} 2 * 0.2+\mathrm{E} 3 * 0.2+\mathrm{E} 4 * 0.3$} \\
\hline
\end{tabular}

Questionnaire. This research uses pretest and posttest questionnaires, which consist of three parts. The design of the questionnaire refers to the development requirements of engineering education for students' competencies [28], [28] and uses Likert's five-point scoring method to count the score, as shown in Table 2. Consider the process of evaluating the questionnaire is subjective, we pay attention to improving the validity and reliability of the questionnaire as much as possible.

Table 2. Description of the questionnaire

\begin{tabular}{|l|l|c|}
\hline Question & \multicolumn{1}{|c|}{ Description } & Number of items \\
\hline $\begin{array}{l}\text { Learning interest in the } \\
\text { project }\end{array}$ & Interest in group learning, interest in artificial intelligence, etc. & 5 \\
\hline $\begin{array}{l}\text { Understanding of } \\
\text { subject knowledge }\end{array}$ & $\begin{array}{l}\text { Ideas for programming, ideas for solving mathematical prob- } \\
\text { lems, etc. }\end{array}$ & 5 \\
\hline $\begin{array}{l}\text { Engineering project } \\
\text { competencies [28] }\end{array}$ & $\begin{array}{l}\text { sign, test, validate, and deliver; } \\
\text { L2: Master the methods and tools needed for engineering } \\
\text { projects to meet the expectations of the project; } \\
\text { L3: Full of teamwork spirit, dare to criticize, question, and } \\
\text { innovate; } \\
\text { L4: Comply with industry standards, social norms, and engi- } \\
\text { neering ethics. }\end{array}$ & 5 \\
\hline
\end{tabular}


Peer Evaluation. In project-based learning, peer evaluation directly reflects the students' enthusiasm for learning. Some scholars divided the evaluation of text types into emotional types and cognitive types [30], as shown in Table 3. . They believe that the learner's effort in cognitive evaluation is more significant than emotional evaluation. In other words, students who give cognitive evaluations are more engaged in learning. Therefore, each student evaluates the performance of others every week with no restrictions on the content of text types. Finally, we count the effective ratio of peer review texts to reflect students' project-based learning results.

Table 3. Type description of peer evaluation

\begin{tabular}{|l|c|c|}
\hline Dimension & Category & Example \\
\hline \multirow{3}{*}{ Emotional type } & Support & You did an excellent job \\
\cline { 2 - 3 } & Disapproval & you did too badly \\
\hline \multirow{3}{*}{ Cognitive type } & Point out the error & Your formula for this step is wrong \\
\cline { 2 - 3 } & Express personal opinions & I think your schematic illustration is well-arranged \\
\cline { 2 - 3 } & Give suggestions & Try adjusting the learning rate of the network model to 0.01 \\
\cline { 2 - 3 } & Analyze skills & $\begin{array}{c}\text { When you do the experiment, your thinking is clear and the } \\
\text { operation is standard }\end{array}$ \\
\hline
\end{tabular}

Project results. The project results can intuitively reflect the effectiveness of the learning model. Moreover, the actual operation part is significant for the education and training of engineering students.

\section{$4 \quad$ Project architecture and students' work}

This section introduces the structure of the artificial intelligence project, focuses on the students' work based on the learning model designed in the previous section, and finally summarizes the STEM group's learning process.

\subsection{Project architecture}

Our research is driven by the realization of intelligent car target tracking to solve the actual project problems, which benefits from the remarkable achievements of convolutional neural networks in computer vision [31]. Students can be familiar with the evolution process from machine learning to deep learning in SQ activity and promote engineering students' understanding of artificial intelligence technology.

Target tracking projects can be divided into three parts: perception, decisionmaking, and control. First, the perception module uses camera sensors to identify the surrounding environment and state of the vehicle and extracts picture information as input to the decision-making module. Then, we use the pre-trained neural network model to achieve target detection and combine the tracking algorithm to obtain the output signal of the decision-making module. Finally, the control module drives the motors to rotate according to the output signal to complete the target tracking of the intelligent car. 
Hardware Components. The intelligent car is called Jetbot, an open-source intelligent car developed by NVIDIA for researchers to use. Its core embedded motherboard is Jetson Nano, equipped with a quad-core Cortex-A57 processor and 128 NVIDIA Maxwell GPUs, 4GB of LPDDR4 memory, providing 472 gigabytes floating-point computing power. The camera used for image acquisition features a Sony IM219 chip with a resolution of 8 million pixels and a wide-angle field of view of 160 degrees. The power module is a DC voltage of $12 \mathrm{~V}$. The movement of the intelligent car is driven by the differential control of the left and right TB6612FN motors, and the follower of the universal bottom wheel cooperates. The hardware components of the intelligent car are flexible and practical and can directly run the Linux system. In addition to the above points, the intelligent car also supports many AI frameworks and TensorRT acceleration functions.

Operating principle. The PC and Jetbot communicate through the local area network. First of all, the car transmits the video data collected by the camera to the PC via wireless signals so that students can view the road conditions on which the car is driving. In the second step, students process each frame of the video in the background of the system and train the neural network model. Finally, students can get the target's label, confidence, and position coordinates to complete the target tracking of the intelligent car. The operating process diagram of the intelligent car sees in Fig. 3.

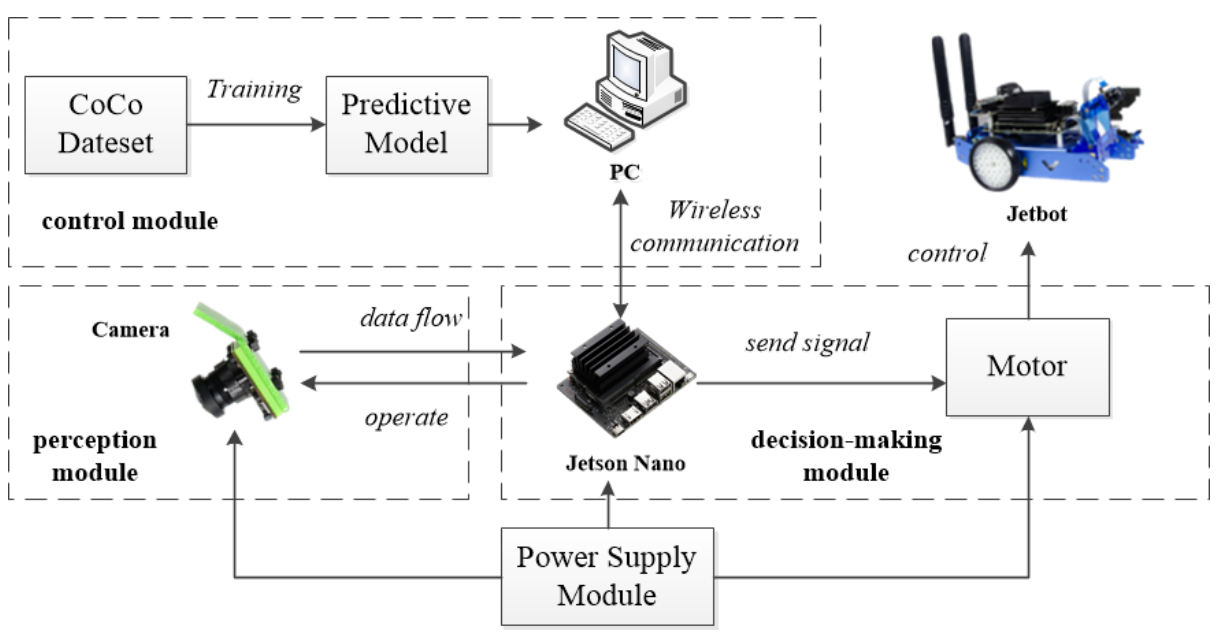

Fig. 3. Operating process diagram of the intelligent car

Experiment Platform. The project uses Python as the programming language. Then, the platform environment is jupyter lab, which supports multiple functional plug-ins. In addition, jupyter lab can be run in the browser or accessed through the client. 


\subsection{Students' work}

According to the project's needs, students choose YOLOv3 to implement the target detection algorithm in LS activity. Because under the same hardware performance, YOLOv3 significantly improves detection speed and accuracy compared to other algorithms [32]. After finding and sorting out relevant technical literature, students enter the SM activity of the SC-STEM-LM. In this activity, students conduct scientific research and mathematical analysis based on the function of the project. One person in the group is responsible for establishing the mathematical model and then drawing the process structure of this sub-project. Next, another person is programming and building a neural network to train the model, including generating the best anchor box and extracting image features. Following that, students construct a loss function and implement a target detection algorithm by solving regression problems.

On the one hand, the above work consolidates the students' existing subject knowledge. On the other hand, simplifying complex project functions into popular mathematical models can deepen their understanding of artificial intelligence technology. In another perspective, the traditional engineering learning methods rely on the machine, and it takes students much time to determine the optimal parameters after repeated iterative attempts. Therefore, the introduction of human participation when solving the optimal strategy of the algorithm, in a human-in-the-loop way, adding intelligent human decision-making can avoid the invalid learning of the machine [33]. The Human-in-the-loop algorithm solution model is shown in Fig. 4.

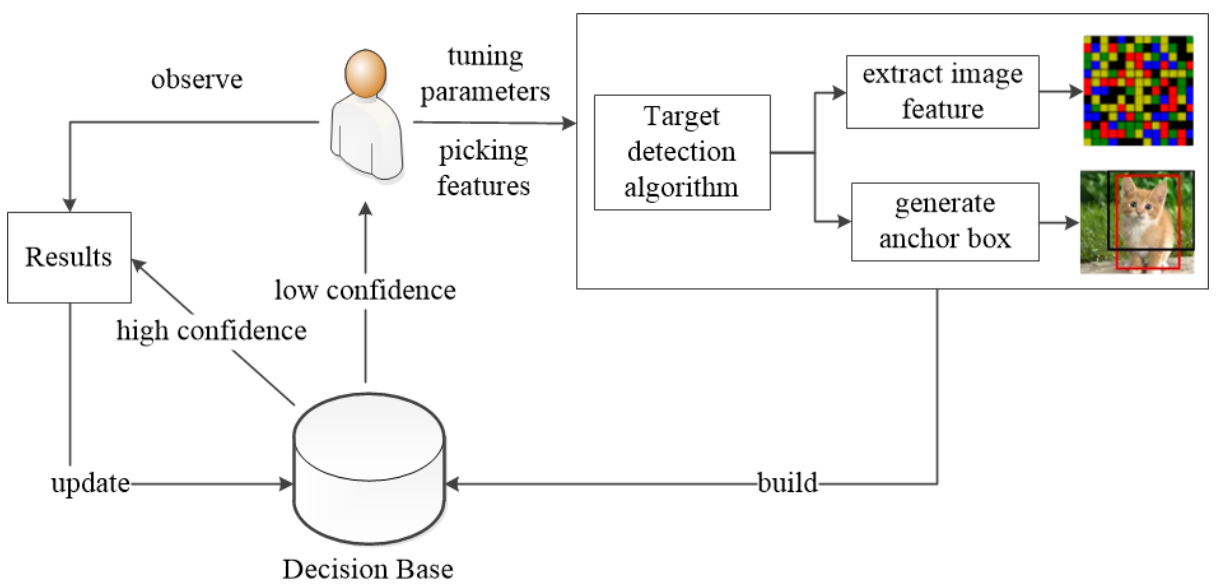

Fig. 4. The human-in-the-loop algorithm solution model

In the ET activity of the SC-STEM-LM, students can control the left and right motor units separately and use the dynamic differential method to realize the car's forward, backward, and left-right steering. The cart moves forward when the speeds of the motors on both sides are the same, and the parameters exceed zero. Otherwise, it moves backward. The core of the target-following algorithm is to make the car always 
follow a relative center point. No matter how deviated from the target, the car can always move towards the target.

Through the design and discussion of the target tracking algorithm, the students summarize as a mathematical formula to express the movement principle of the intelligent car:

$$
\text { Move }_{\text {jetbot }}=\left\{\text { speed }+ \text { turn }_{w} * \text { center }_{x} \mid \text { speed }- \text { turn }_{w} * \text { center }_{x}\right\},
$$

where center $_{x}$ is the offset of the horizontal position. Based on the movement of the intelligent car, students scientifically adjust the size of $t u r n_{w}$ to find the best parameters suitable for the experimental scene.

After completing the above theoretical analysis, students begin coding on Jupyter Lab. Subsequently, they verify the operation effect of the car in the actual scene. At the same time, other members are responsible for recording, analyzing experimental data, and submitting them in project reports. In the end, under the guidance of the SCSTEM-LM, the students achieve the expected project functions. From the overall learning process perspective, students improve their abilities with the continuous integration and refinement of interdisciplinary knowledge, which serves as the foundation to support the entire project. Meanwhile, the realization of the project also promotes the development of disciplinary knowledge. The design structure of the project is shown in Fig. 5.

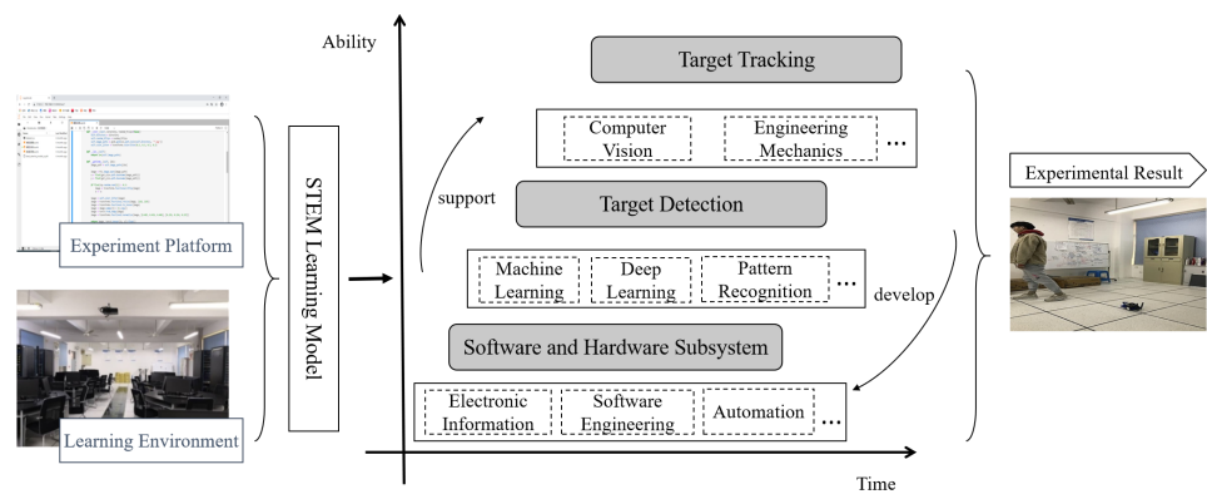

Fig. 5. The design structure of a intelligent car to achieve target tracking

In the CI activity of the SC-STEM-LM, students find that with the rapid switching of scenes, the efficiency of the target detection algorithm cannot satisfy the real-time requirements, and the intelligent car was delayed or lost the target. In addition, the intelligent car realizes the conversion from the input of the deviation value to the actuator's output, but the fast steering makes the movement of the car very stiff. Due to these problems, the STEM group tried redefining the problem and searching for helpful literature to make the car track the target more smoothly. By reconstructing the knowledge system and continuous thinking, they introduced the PID algorithm [34] to solve the intelligent car's insensitivity problem and improve the innovation ability. 


\subsection{Summary of the student-centered STEM learning model}

We summarized the complete learning process as shown in Table 4. .

Table 4. Summary of the student-centered STEM learning model

\begin{tabular}{|c|c|c|}
\hline $\begin{array}{l}\text { Learning } \\
\text { Activities }\end{array}$ & Learning Content & Learning outcome \\
\hline \multirow{2}{*}{ 1. SQ } & $\begin{array}{l}\text { 1.1 Enter the situation: The application of artificial intelligence is } \\
\text { valuable }\end{array}$ & \multirow{2}{*}{$\begin{array}{l}\text { To stimulate interest in } \\
\text { learning }\end{array}$} \\
\hline & $\begin{array}{l}\text { 1.2 Ask questions: How to achieve the target tracking of the } \\
\text { intelligent car }\end{array}$ & \\
\hline \multirow[t]{2}{*}{ 2. LS } & $\begin{array}{l}\text { 2.1 Search literature: Understand the current mainstream technical } \\
\text { methods }\end{array}$ & \multirow{2}{*}{$\begin{array}{l}\text { To cultivate information } \\
\text { awareness and team } \\
\text { leadership }\end{array}$} \\
\hline & 2.2 Set strategy: Assign tasks and list project plans & \\
\hline \multirow{4}{*}{ 3. ET } & $\begin{array}{l}\text { 3.1 Divide the project into three parts : perception, decision- } \\
\text { making, and control }\end{array}$ & \multirow{4}{*}{$\begin{array}{l}\text { To master new technolo- } \\
\text { gy, cultivate practical } \\
\text { ability }\end{array}$} \\
\hline & $\begin{array}{l}\text { 3.2 Assemble the intelligent car and handle the interaction be- } \\
\text { tween the devices }\end{array}$ & \\
\hline & 3.3 Coding: Training a deep neural network model & \\
\hline & 3.4 Doing experiment: Test, record data, and analyze the reason & \\
\hline \multirow{2}{*}{ 4. SM } & $\begin{array}{l}\text { 4.1 Use mathematical language to describe the essence of intelli- } \\
\text { gent car movement }\end{array}$ & \multirow{2}{*}{$\begin{array}{l}\text { To cultivate problem- } \\
\text { solving skills }\end{array}$} \\
\hline & $\begin{array}{l}\text { 4.2 Adjust the speed and steering of the intelligent car by solving } \\
\text { mathematical problems }\end{array}$ & \\
\hline 5. TS & $\begin{array}{l}\text { 5.1 Communicate and think regularly in the form of a team every } \\
\text { day }\end{array}$ & $\begin{array}{l}\text { To cultivate the ability of } \\
\text { teamwork }\end{array}$ \\
\hline \multirow{2}{*}{ 6. CI } & $\begin{array}{l}\text { 6.1 Expand knowledge: Learn more about other fields related } \\
\text { knowledge }\end{array}$ & \multirow{2}{*}{$\begin{array}{l}\text { To cultivate innovative } \\
\text { ability }\end{array}$} \\
\hline & $\begin{array}{l}\text { 6.2 Use the PID module in the principle of automation control to } \\
\text { improve the intelligent car }\end{array}$ & \\
\hline 7. EA & $\begin{array}{c}\text { 7.1 Questionnaire; 7.2 Peer evaluation; } 7.3 \text { Periodic reports; } 7.4 \\
\text { Project results }\end{array}$ & $\begin{array}{l}\text { To evaluate the effect of } \\
\text { learning }\end{array}$ \\
\hline
\end{tabular}

We also listed the specific STEM performance as follows:

1. Science: Students cultivated the spirit of collaborative inquiry and information awareness by assembling intelligent cars, collecting relevant documents, and assigning project tasks.

2. Technology: Students designing algorithm models, programming tests, and building deep neural networks Deepen students' understanding of artificial intelligence technology.

3. Engineering: Students cultivate engineering operation ability and stimulate innovative thinking by drawing project flowcharts, analyzing experimental data, and improving project results.

4. Mathematics: Students pass mathematics knowledge assists the implementation of the project, guides the feasibility of the project on a theoretical level, and cultivates the ability of computational thinking and problem analysis. 


\section{Discussion}

This section aims to prove the effectiveness of the newly designed learning model and conduct specific discussions on research issues. We use a weighted multievaluation algorithm throughout project-based learning. See section 3.3 for details. This research adopts a quantitative and qualitative hybrid analysis method. The following content is introduced from four aspects: periodic reports, questionnaires, peer evaluation, and project results.

\subsection{Periodic reports}

After the first round of scoring, we use the Cohen Kappa [35] coefficient to measure the consistency of the two instructors. The results of the consistency test of the two instructors are shown in Table 5. $(k=0.5, p<0.001)$, which are statistically significant. Thus, the instructors' evaluation results are credible and belong to moderate consistency.

Table 5. Symmetric measures on scoring of instructors

\begin{tabular}{|c|c|c|c|c|c|}
\hline \multicolumn{2}{|l|}{} & Value & $\begin{array}{c}\text { Asymptotic Stand- } \\
\text { ard Errora }\end{array}$ & Approximate Tb & $\begin{array}{c}\text { Approximate Signif- } \\
\text { icance }\end{array}$ \\
\hline $\begin{array}{c}\text { Measure of } \\
\text { Agreement }\end{array}$ & Kappa & .500 & .179 & 3.333 & .001 \\
\hline \multicolumn{2}{|c|}{ N of Valid Cases } & 10 & - & - & - \\
\hline
\end{tabular}

Following that, we count the three rounds of scores of the STEM learning group and the traditional learning group ('A' represents 5 points and decreases in order) and use the average score to reflect everyone's contribution. We plot each group's learning trend under the instructor's evaluation, as shown in Fig. 6. Where "item1" represents the score for the content of the submitted document, and "item2" means the score for the student's ability to express and summarize. We can see from the figure that the students' expression and summary ability are on the rise. Fortunately, judging from the research results of the learning pyramid, students' expressive ability (saying) is advantageous in mastering knowledge. It also means that as the project progresses, students' understanding of artificial intelligence technology is also improving, and the experimental group's achievements are significantly better than the control group. However, there is no substantive change in students' abilities from the content of the documents submitted. 
(a) experimental group

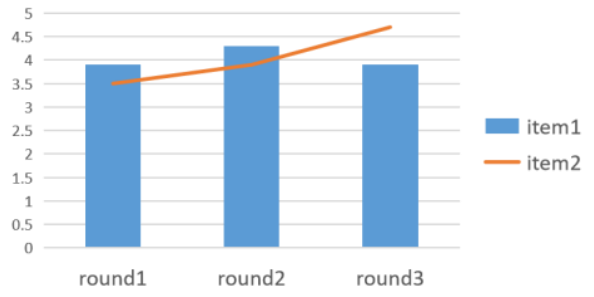

(b) control group

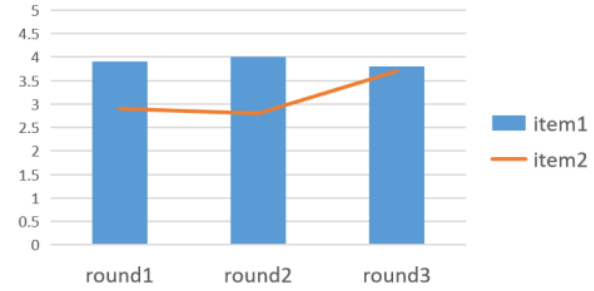

Fig. 6. The learning trend of each group with the evaluation of the instructor

In addition, we also count the scores of each student. Fig. 7 reflects the differences in individual learning. At first, the scores were evenly distributed between 5-9 and then gradually concentrated. No matter how complicated and changeable the process is, it is gratifying that students' performance develops in this promising direction. In particular, the results of the STEM group are more outstanding, which benefits from a good learning atmosphere.

(a) experimental group

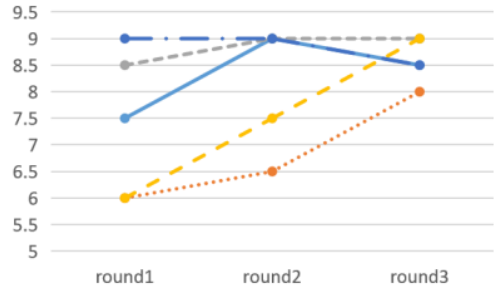

(b) control group

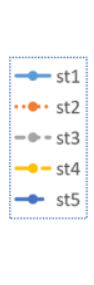

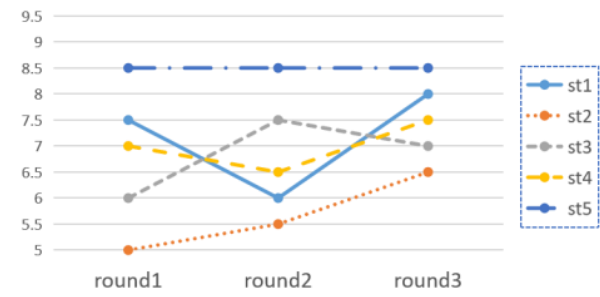

Fig. 7. The scoring trend of each student

\subsection{Questionnaire}

We perform a paired sample T-test on the experimental group [36]. Table 6. counts the information about students' answers in the pre-and post-test questionnaire, including three aspects and total scores. The post-test score is higher than the pre-test level from students' interest in artificial intelligence projects, and the sample means different and significantly correlated $(\mathrm{p}<0.05)$. Next, from the students' understanding of subject knowledge, the post-test score is higher than the pre-test level, and the sample means different and extremely correlated $(\mathrm{p}<0.01)$. Moreover, from the students' scores on engineering projectability, the post-test score is significantly higher than the pre-test, which is extremely correlated $(\mathrm{p}<0.01)$. Finally, the results show that students' satisfaction is significant within the $95 \%$ confidence interval after adopting the SC-STEM-LM. 
Paper-The Student-Centered STEM Learning Model Based on Artificial Intelligence Project: A Case...

Table 6. Paired samples T-test on STEM learning group

\begin{tabular}{|l|c|c|c|c|c|c|c|}
\hline \multirow{2}{*}{} & \multicolumn{2}{|c|}{ Pretest } & \multicolumn{2}{c|}{ Posttes } & \multicolumn{3}{c|}{ Paired Samples Test } \\
\cline { 2 - 8 } & Mean & S.D. & Mean & S.D. & $\boldsymbol{t}$ & Sig. & Correlation \\
\hline Learning interest in the project & 14.4 & 3.975 & 21.4 & 2.510 & -5.217 & .006 & .657 \\
\hline Understanding of subject knowledge & 14.4 & 1.673 & 19.8 & 1.304 & -7.962 & .001 & .504 \\
\hline Engineering project competencies & 13.2 & 1.924 & 19.8 & .837 & -9.731 & .001 & .652 \\
\hline Totals & 42 & 1.581 & 61 & 1.225 & -20.028 & .000 & .486 \\
\hline
\end{tabular}

Similarly, we use the independent sample Test to evaluate the difference in learning effects of different groups, as shown in Table 7 . . The results show that the score of the STEM learning group is $(61.0 \pm 1.23)$, and the score of the traditional learning group is (57.2 \pm 0.84$)$. Therefore, we consider that different learning models have statistically significant differences in student abilities $\left(t^{\prime}=5.729, \mathrm{p}<0.01\right)$.

Table 7. T-test results comparing the learning effects of the two groups

\begin{tabular}{|c|c|c|c|c|c|c|}
\hline \multicolumn{2}{|c|}{$\begin{array}{c}\text { Control } \\
\text { Group }\end{array}$} & \multicolumn{2}{c|}{$\begin{array}{c}\text { Experimental } \\
\text { group }\end{array}$} & \multicolumn{3}{c|}{ Independent Samples Test } \\
\hline Mean & S.D. & Mean & S.D. & $\mathrm{t}$ & $\mathrm{df}$ & Sig. \\
\hline 57.20 & .837 & 61.00 & 1.225 & 5.729 & 7.066 & .001 \\
\hline
\end{tabular}

\subsection{Peer evaluation}

This research collected a total of 200 feedback messages evaluated by peers. We count the type frequency of each group of submitted and displayed the distribution of each evaluation text with different types of lines, as shown in Fig. 8. We find that students like to give supportive comments that express strong emotions but do not like to give negative comments. There are 25 emotion types in the experimental group and 40 emotion types in the control group. From the evaluation of cognitive types, most students like to express their personal opinions, and the behaviors of giving amendments and pointing out other people's mistakes are relatively small. However, we follow that students' effort on cognitive evaluation is greater than that of emotional evaluation. Therefore, although some students actively completed the evaluation task, they are not deeply involved in the learning. The results showed that the learning interest of the experimental group students was significantly higher than that of the control group. 
(a) experimental group

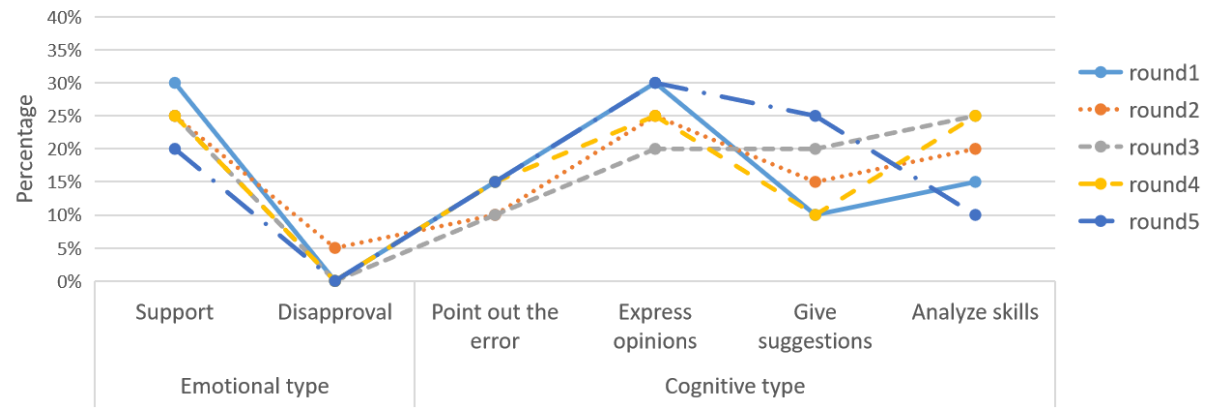

(b) control group

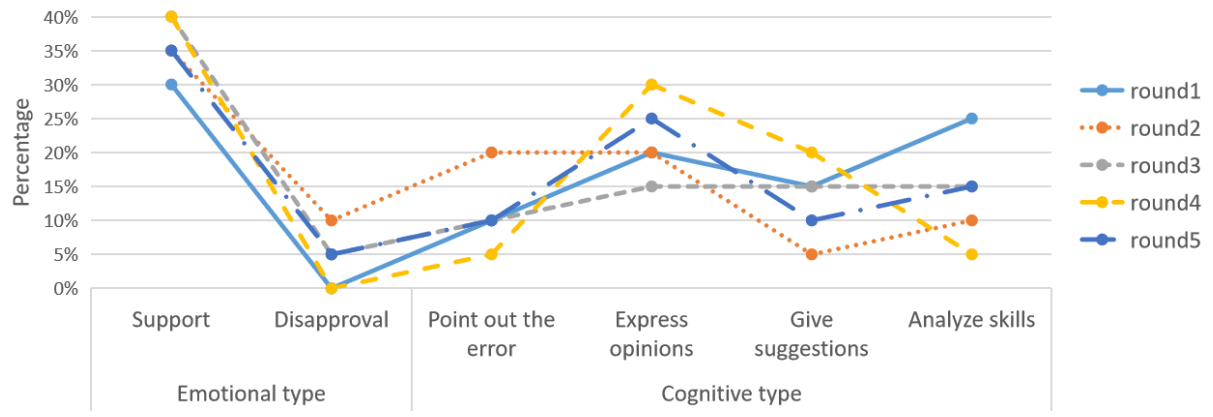

Fig. 8. Distribution of text types in peer evaluation

\subsection{Project results}

The intelligent car often loses the target in tracking, which requires manual intervention to adjust the car position. Thus, students record the number of human interventions by the intelligent car within one minute, and then according to the formula:

$$
\text { Accuracy }=1-\frac{\text { loss } * \text { numbers }}{T}
$$

to calculate the accuracy of the target tracking algorithm, where loss represents the time, and it takes for people to re-adjust the position of the car. Then, we take the best score after multiple experiments as the score of the project result. Furthermore, through constant trial and error and improvement, engineering students have also discovered the applicable scenarios and defects of the target tracking algorithm. In this way, they can better improve their abilities and deepen their understanding of artificial intelligence technology.

Integrate the above four aspects, and Table 8. shows the results of the weighted multi-evaluation algorithm in the two learning groups. The STEM learning group has certain advantages over the control group, achieving 82.84 points. The empirical analysis shows that the SC-STEM-LM can promote the learning effect of emerging engineering students and improve the application ability of knowledge. 
Paper-The Student-Centered STEM Learning Model Based on Artificial Intelligence Project: A Case..

Table 8. The comparative evaluation results of the two study groups

\begin{tabular}{|l|l|c|l|c|}
\hline \multicolumn{1}{|c|}{ Evaluation Method } & \multicolumn{2}{|c|}{ Experimental Group } & \multicolumn{2}{c|}{ Control Group } \\
\hline Periodic Reports & average score & 80.67 & average score & 70.33 \\
\hline Questionnaire & satisfaction score & $81.33 \%$ & satisfaction score & $76.27 \%$ \\
\hline Peer Evaluation & $\begin{array}{l}\text { percentage of effective } \\
\text { copies }\end{array}$ & $75 \%$ & $\begin{array}{l}\text { percentage of effective } \\
\text { copies }\end{array}$ & $60 \%$ \\
\hline Project Results & accuracy & $91.25 \%$ & accuracy & $85.42 \%$ \\
\hline Total score & \multicolumn{2}{|c|}{73.98} \\
\hline
\end{tabular}

Our research has shown that the SC-STEM-LM can enhance students' enthusiasm for learning, speed up students' absorption and mastery of knowledge, and promote innovative abilities. From the instructors' evaluation and questionnaire results, since the implementation process of the artificial intelligence project has broken the problem of the original professional courses that are difficult to connect [37], the student's understanding of knowledge has been improved. Furthermore, many scholars responded to the call of the national policy [16]. They widely used educational robots in the context of the new engineering reform [5], prompting students to be more optimistic about the new learning model [9]. Moreover, peer evaluation results show that the blending learning method based on intelligent robots arouses students' enthusiasm and increases their investment in learning. For this reason, more and more research attempts have been shifting towards student-centric [23], so it is essential to establish an environment for creative learning and personalized student development [19].

From the project results, the experimental group has a higher accuracy rate in realizing the target tracking algorithm of the intelligent car, which benefits from the advantages of STEM in the development of innovative capabilities [4]. From another perspective, the experimental group take five weeks to complete the project functions ahead of schedule, bringing more innovation opportunities. In addition, students have reliance and negative thoughts in group learning. Therefore, teachers should assume the role of learning supervisor, enhance communication with students and be aware of the advantages of emerging technologies [25].

Our research believes that the SC-STEM-LM integrates multiple disciplines and uses projects as a carrier to comprehensively use complex and scattered knowledge, conducive to improving engineering students' application and research capabilities. Shortly, educational activities are likely to achieve popularization and humanization of scientific development with the help of artificial intelligence technology [37]. Therefore, we have further explored the application of blended learning models in engineering education.

\section{Conclusions}

This research realizes the target tracking of the intelligent car by using the SCSTEM-LM. In addition, we have also designed a new weighted multi-evaluation algorithm to measure students' learning effects from different angles. In the periodic reports, the instructors fully affirmed the learning effect of the two groups. The STEM 
group scored 80.67 , which was higher than the control group. In the questionnaire, the satisfaction rate of the STEM group was $81.33 \%$, while that of the control group was only $76.27 \%$. In peer evaluation, two groups of students improved their cognitive participation behaviors, and the performance of the STEM group was prominent. Finally, from the project results, the speed of the STEM group is faster, and the accuracy of the intelligent car tracking algorithm is $91.25 \%$, which is $5.83 \%$ higher than that of the control group, which shows that they have strong innovation ability.

Besides the above results, our research elaborates the theoretical framework, such as project theme selection, student work, and multi-evaluation algorithm. However, we still find that individual students have learning burnout because the differences in students' self-efficacy affect their initiative to participate in learning [22]. Improving courses' quality to encourage students to participate in education activities is often inefficient [15]. Therefore, we can enhance students' self-efficacy through gamification [24], digitization, and intelligent devices. In addition, the sample size of this research is relatively small, and the learning model is limited to engineering majors, which are also the directions of follow-up research that need to be improved. Considering that Li of Stanford University launched the "Human-Centered AI initiative," thinking artificial intelligence's sound development needs humanistic guidance [38]. Therefore, we can also use STEAM education as a development path, and students majoring in humanities and arts can also join in the learning.

We have been actively exploring the application model of STEM in engineering education and integrating it into daily teaching. With the popularization of educational technology, we can also expand the scope of this research and encourage more students to join in response to the shortcomings mentioned above. Because for the academic community, it would be an informed decision to introduce intelligent projects or robotic kits into the classroom [39]. This research is of great significance to students' growth and provides an effective practice plan for the theoretical innovation of emerging engineering education.

\section{$7 \quad$ Acknowledgment}

This work was supported by the Fujian Province Nature Science Foundation under Grant No.2020J01813, the Zhangzhou Municipal Natural Science Foundation under Grant ZZ2021J23, and the Research Project on Education and Teaching Reform of Undergraduate Colleges and Universities in Fujian Province under Grant FBJG20210070.

\section{$8 \quad$ References}

[1] Ben, G. (2014). Artificial General Intelligence: Concept, State of the Art, and Future Prospects. Journal of Artificial General Intelligence, 5(1):1-48. http://doi.org/10.2478/jagi2014-0001

[2] Fengguang Jiang, Bolong Xiong, Chao Zhang. (2020). How China's Artificial Intelligence Achieves Strategic Breakthrough---The Comparison and Interpretation of Four Arti- 
Paper-The Student-Centered STEM Learning Model Based on Artificial Intelligence Project: A Case...

ficial Intelligence Development Reports Between China and the United States. Moden Distence Education Research, 32(1):3-11.

[3] Taotang Liu, Zhongxin Gao, Honghai, Guan. (2021). Educational Information System Optimization for Artificial Intelligence Teaching Strategies. Complexity, 3:1-13. http://doi. org $/ 10.1155 / 2021 / 5588650$

[4] Yonghe Wu, Ruochen Li, Haonan Wang, et al. (2018). Research on the Cultivation of College Students' Innovative Ability Based on STEM Education---An Empirical Study on the Application of R Language and 3D Printing in Advanced Mathematics. Modern Distance Education Research, 5:77-85,112. https://doi.org/10.3969/j.issn.1009-5195.2018.05.009

[5] Xiaoming Cao. (2018). Intelligence + School: New Pattern of School under the Perspective of Educational Informatization 2.0. Journal of Distance Education, 36(4):57-68. https://doi.org/10.15881/j.cnki.cn33-1304/g4.2018.04.008

[6] Stuikys, V., Burbaite, R., Drasute, V., et al. (2019). A Framework for Introducing Personalisation into STEM- Driven Computer Science Education. The international journal of engineering education, 35(4):1176-1193. https://doi.org/10.1109/educon.2018.8363456

[7] Yewei Tang, Liting Guo, Yueguang Xie, et al. (2017). Research on STEM Interdisciplinary Integration Model Based on Educational Artificial Intelligence. China Educational Technology, 8:46-52. https://doi.org/10.26914/c.cnkihy.2020.009006

[8] Papadakis, S. (2020). Evaluating a Teaching Intervention for Teaching STEM and Programming Concepts Through the Creation of a Weather-Forecast App for Smart Mobile Devices. In M. Kalogiannakis, \& S. Papadakis (Eds.), Handbook of Research on Tools for Teaching Computational Thinking in P-12 Education, 31-53. IGI Global. https://doi. org/10.4018/978-1-7998-4576-8.ch002

[9] Huang Suo. (2021). Design and Development of Educational Robot Teaching Resources Using Artificial Intelligence Technology. International Journal of Emerging Technologies in Learning (iJET), 16(5):116-129. https://doi.org/10.3991/ijet.v16i05.20311

[10] Yewei Tang, Liting Guo, Yueguang Xie, et al. (2017). Research on STEM Interdisciplinary Integration Model Based on Educational Artificial Intelligence. China Educational Technology, 8:46-52. https://doi.org/10.26914/c.cnkihy.2020.009006

[11] Birzina, R., Pigozne, T., Lapina, S. (2021). Trends in STEM Teaching and Learning within the Context of National Education Reform. 14th International Scientific Conference "Rural Environment. Education. Personality. (REEP)". https://doi.org/10.22616/reep.2021.14.004

[12] Almulla, M. A. (2020). The Effectiveness of the Project-Based Learning (PBL) Approach as a Way to Engage Students in Learning. SAGE Open, 10:1-15. https://doi.org/10.1177/ 2158244020938702

[13] Becker, S. A., Cummins, M., Davis, A., et al. (2017). NMC Horizon Report: 2017 Higher Education Edition. Journal of Open Learning.

[14] Yanez, G. A., Thumlert, K., Jenson, J., et al. (2019). Pathways to sustainable futures: A "Production Pedagogy" Model for STEM Education. Futures, 108(4):27-36. https://doi. org/10.1016/j.futures.2019.02.021

[15] Maltese, A. V., Tai, R. H. (2011). Pipeline persistence: Examining the association of educational experiences with earned degrees in STEM among U.S. students. Science Education, 95(5):877-907. https://doi.org/10.1002/sce.20441

[16] Gough, Annette. (2015). STEM policy and science education: scientistic curriculum and sociopolitical silences. Cultural Studies of Science Education, 10(2):445-458. https://doi.org/10.1007/s11422-014-9590-3

[17] Peng Chen, Yang Tian, Ronghuai Huang. (2019). An Interdisciplinary STEM Case Study and Its Enlightenments Based on Design Thinking---A Case of STEM Course in d.loft 
Paper-The Student-Centered STEM Learning Model Based on Artificial Intelligence Project: A Case...

STEM Project of Stanford University. China Educational Technology, 8:82-90. https://doi.org/10.3969/j.issn.1006-9860.2019.08.013

[18] Papadakis, S., Vaiopoulou, J., Sifaki, E., et al. (2021). Attitudes towards the Use of Educational Robotics: Exploring Pre-Service and In-Service Early Childhood Teacher Profiles. Education Sciences, 11(5):204. https://doi.org/10.3390/educsci11050204

[19] Togou, M. A., Lorenzo, C., Cornetta, G., et al. (2019). Assessing the Effectiveness of Using Fab Lab-based Learning in Schools on K-12 Students' Attitude Toward STEAM. IEEE Transactions on Education. https://doi.org/10.1109/TE.2019.2957711

[20] Dasgupta, C., Magana, A. J., Vieira, C. (2019). Investigating the affordances of a CAD enabled learning environment for promoting integrated STEM learning. Computers \& Education, 129:122-142. https://doi.org/10.1016/j.compedu.2018.10.014

[21] Liangfu Jiang, Haoran Yuan. (2021). Stable Parallel Algorithms for Interdisciplinary Computer-Based Online Education with Real Problem Scenarios for STEM Education. Complexity, 1:1-12. https://doi.org/10.1155/2021/5432703

[22] Han, J., Kelley, T., Knowles, J. G. (2021). Factors Influencing Student STEM Learning: Self-Efficacy and Outcome Expectancy, 21 st Century Skills, and Career Awareness. Journal for STEM Education Research, 1-21. https://doi.org/10.1007/s41979-021-00053-3

[23] Hasnine, M. N., Hussien, M. M., Ueda, H. (2021). Learner-centric Technologies to Support Active Learning Activity Design in New Education Normal: Exploring the Disadvantageous Educational Contexts. International Journal of Emerging Technologies in Learning (iJET), 16(10):150-162. https://doi.org/10.3991/ijet.v16i10.20081

[24] Kalogiannakis, M., Papadakis, S. J., Zourmpakis, A. I. (2021). Gamification in Science Education. A Systematic Review of the Literature, Education Sciences. 11(22):1-36. https://doi.org/10.3390/educsci11010022

[25] Papadakis, S., Vaiopoulou, J., Sifaki, E., et al. (2021). Factors That Hinder in-Service Teachers from Incorporating Educational Robotics into Their Daily or Future Teaching Practice. In CSEDU (2), 55-63. https://doi.org/10.5220/0010413900550063

[26] Changya Liu. (2019). Accelerating the Modernization of Education and Embarking on a New Journey to Build a Strong Country for Education---An Interpretation of China's Modernization of Education 2035. The Journal of Educational Research, 40(11):4-16.

[27] Guangde Xiao, Xiongying Wei, Ronghuai Huang. (2017). Suggestions on Curriculum Evaluation Oriented to Discipline Core Literacy of Information Technology in High School. China Educational Technology, 1:33-37. https://doi.org/10.3969/j.issn.1006$\underline{9860.2017 .01 .006}$

[28] Mcgowan, V. C., Bell, P. (2020). Engineering Education as the Development of Critical Sociotechnical Literacy. Science and Education, 29(4):981-1005. https://doi.org/10.1007/ $\underline{\mathrm{s} 11191-020-00151-5}$

[29] Jacques, S., Bissey, S., Martin, A. (2016). Multidisciplinary Project Based Learning Within a Collaborative Framework: A Case Study on Urban Drone Conception. International Journal of Emerging Technologies in Learning (iJET), 11(12):36-44. https://doi.org/10. 3991/ijet.v11i12.5996

[30] Nelson, M. M., Schunn, C. D. (2009). The nature of feedback: how different types of peer feedback affect writing performance. Instructional Science, 37(4):375-401. https://doi.org/ 10.1007/s11251-008-9053-x

[31] Brunetti, A., Buongiorno, D., Trotta, G. F., et al. (2018). Computer vision and deep learning techniques for pedestrian detection and tracking: A survey. Neurocomputing, 300(26):17-33. https://doi.org/10.1016/j.neucom.2018.01.092 
Paper-The Student-Centered STEM Learning Model Based on Artificial Intelligence Project: A Case...

[32] Dang, L., Nguyen, G. T., Cao, T., et al. (2020). Object Tracking Using Improved DeepSort-YOLOv3 Architecture. ICIC Express Letters, 14(10):961-969. https://doi.org/10. 24507/icicel.14.10.961

[33] Honeycutt, D., Nourani, M., Ragan, E. (2020). Soliciting Human-in-the-Loop User Feedback for Interactive Machine Learning Reduces User Trust and Impressions of Model Accuracy. Proceedings of the AAAI Conference on Human Computation and Crowdsourcing, $8(1): 63-72$.

[34] Farag, W. (2019). Complex Trajectory Tracking Using PID Control for Autonomous Driving. International Journal of Intelligent Transportation Systems Research, 18(2). https://doi.org/10.1007/s13177-019-00204-2

[35] Sun, S. (2011). Meta-analysis of Cohen's kappa. Health Services and Outcomes Research Methodology, 11(3-4):145-163. https://doi.org/10.1007/s10742-011-0077-3

[36] Ceylan, S., Ozdilek, Z. (2015). Improving a Sample Lesson Plan for Secondary Science Courses within the STEM Education. Procedia - Social and Behavioral Sciences, 177(22):223-228. https://doi.org/10.1016/j.sbspro.2015.02.395

[37] Liu, J. (2020). How Can Artificial Intelligence make Education Research Move Forward to Science. Research in Higher Education of Engineering, 180(1):106-117.

[38] Wei, Xu. (2019). Toward Human-Centered AI: A Perspective from Human-Computer Interaction. Interactions, 26(4):42-46. https://doi.org/10.1145/3328485

[39] Papadakis, S. (2020). Robots and Robotics Kits for Early Childhood and First School Age. International Journal of Interactive Mobile Technologies (iJIM), 14(18):34-56. https://doi. org/10.3991/ijim.v14i18.16631

\section{Authors}

Jianxin Liao is currently pursuing the Master Degree Candidate at Computer Science of Minnan Normal University and a member of Key Laboratory of Data Science and Intelligence Application, Zhangzhou, P.R.China. His research interests include educational technology and computer vision.

Jingmin Yang is an associate professor at Minnan Normal University of Computer Science, 36 Xianqianzhi Road, Xiangcheng District, Zhangzhou, 363000, P.R.China. At the same time, he is also a visiting researcher at the Fujian Provincial Key Laboratory of Network Security and Cryptography, Fujian Normal University, Fuzhou, P.R.China. His research interests include hardware-software co-design of embedded systems, machine learning, wireless communications and networks.

Wenjie Zhang is a full professor at Minnan Normal University and a member of Key Laboratory of Data Science and Intelligence Application, Zhangzhou, P.R.China. His research interests include Cognitive Radio Network, Wireless Communications and Networks.

Article submitted 2021-06-27. Resubmitted 2021-08-02. Final acceptance 2021-08-02. Final version published as submitted by the authors. 